\title{
Leitura e produção de textos digitais: uma abordagem multimidiática do gênero meme
}

\author{
Lectura y producción de textos digitales: un enfoque \\ multimidiano del género meme
}

\section{Reading and writing of digital texts: a multimedia approach of the genre meme}

\author{
Danielly de Almeida* \\ Tuanny Gomes Siqueira Amaral**
}

\begin{abstract}
RESUMO: O presente trabalho tem como principal objetivo apresentar uma proposta didática para o trabalho com o gênero meme, numa perspectiva multimidiática. Tal estudo se faz necessário devido ao impacto que o gênero causa em redes sociais, dentre as quais destacamos o Facebook como foco de nossa pesquisa. Dentro dessa perspectiva, propomos o trabalho com o gênero meme para o ensino de língua inglesa e, por meio de estratégias baseadas em estudos do letramento digital e dos multiletramentos, juntamente à vertente didática do Interacionismo Sociodiscursivo, elaboramos uma Sequência didática que permita explorar as características do gênero para sua leitura e produção textual.
\end{abstract}

PALAVRAS-CHAVE: Meme. Sequência didática. Multiletramentos.

RESUMEN: El presente trabajo tiene como principal objetivo presentar una propuesta didáctica para el trabajo con el género meme, en una perspectiva multimidiática. Tal el estudio se hace necesario debido al impacto que el género causa en redes sociales, entre las que destacamos a Facebook como foco de nuestra investigación. Dentro de ella perspectiva, proponemos el trabajo con el género meme para la enseñanza de lengua inglesa y, a través de estrategias basadas en estudios del fonograma digital y de los multiletramentos, junto a la vertiente didáctica del Interaccionismo Sociodiscursivo, elaboramos una Secuencia didáctica que permita explorar las características del género para su lectura y producción textual.

PALABRAS CLAVE: Meme. Secuencia didáctica. Multiletramentos.

ABSTRACT: The present paper aims to present a didactic proposal for teaching the genre meme, in a multimedia perspective. This study is necessary because of the

*Mestra em Estudos da Linguagem pelo PPGEL-UEL - Universidade Estadual de Londrina. Professora de língua inglesa/ SEED-PR. daniellyalmeidadmnd@gmail.com

**Mestra em Estudos da Linguagem pelo PPGEL-UEL - Universidade Estadual de Londrina. Orientadora de oficinas de letramento - SESC - Cornélio Procópio. tuanny.gsamaral@gmail.com 
impact that the gender has been doing on social networks recently, among which we highlighted Facebook as the focus of our research. From this perspective, we propose the work with the meme genre for English language teaching and, through strategies based on digital literacy and multiliteracies studies, along with the didactic perspective of Sociodiscursive Interactionism, we elaborate a didactic sequence that allows us to explore the characteristics of the genre for its reading and writing.

KEYWORDS: Meme. Didactic sequence. Multiliteracies.

\section{Introdução}

Com a sociedade tecnológica que vivenciamos hoje, considera-se quase indispensável o domínio do ambiente virtual para que se obtenha sucesso em tarefas cotidianas como efetuar o pagamento de contas, fazer compras ou mesmo ficar a par de fatos recentes ao redor do mundo. Tais tarefas requerem do usuário diversas habilidades que outrora não eram necessárias, fazendo com que, frente às transformações a que estamos submetidos enquanto sociedade, o ensino/aprendizagem tome diferentes proporções (BARRETO, 2006).

A cada dia, mais ferramentas que possibilitam conectividade estão acessíveis às mais diversas camadas sociais. Havendo, também, a previsão de que em alguns anos, certos dispositivos sejam ainda mais consumidos, visto que estatísticas os apontam como mais potentes e baratos ao consumidor no futuro (SCHULER; WINTERS; WEST, 2013).

Considerando este cenário, o objetivo principal deste trabalho é apresentar uma proposta que vise ao aprendizado de línguas por meio de gêneros digitais, pensando em como podemos realizar práticas de ensino/aprendizagem com o uso de recursos tecnológicos como mediadores. Mais especificamente, analisaremos com atenção a virtualidade de redes sociais como o Facebook, o qual veicula com mais frequência um gênero textual que tem muito destaque entre os jovens, o meme.

Para tanto, elaboramos um conjunto de atividades baseadas no construto teórico metodológico do Interacionismo Sociodiscursivo (ISD) (BRONCKART, 1999; 2003; 2009), adotando a engenharia didática para o ensino de gêneros proposta por Dolz, Noverraz e Schneuwly (2004), a saber: sequência didática (SD). Além disso, consideramos o contexto da Cibercultura e 
a sociedade tecnológica, propondo uma prática pedagógica relacionada aos estudos dos multiletramentos.

Tal proposta foi elaborada a partir de um público previsto: alunos do Ensino Médio da rede pública, pois, por atuarmos neste contexto, conhecemos a necessidade de se modificar paradigmas instituídos sobre como se concebe 0 ensino, especialmente no que tange à língua inglesa. Assim, com este trabalho, buscamos reafirmar a relevância do inglês para a ação em sociedade, principalmente considerando sua relação com ferramentas tecnológicas, de modo a promover um ensino reflexivo e significativo aos alunos.

\section{Referencial teórico}

Considerando o referencial adotado, trataremos aqui sobre o estudo dos gêneros sob a vertente do ISD, sobre as novas tecnologias e suas implicações para o ensino de línguas, sobre as práticas de multiletramentos e, por fim, sobre o gênero meme e um de seus contextos de circulação social, o Facebook.

\section{Os Estudos do Gênero e o ISD}

O ensino de línguas, atualmente, tem dado ênfase à necessidade de os sujeitos interagirem ativamente pelo discurso, vendo o texto como objeto de estudo a partir do qual se realizarão as atividades em sala de aula, ou seja, o ensino recai sobre a utilização dos gêneros do discurso ${ }^{1}$ (BAKHTIN, 2003). Dentre as variadas correntes que estudam as manifestações do gênero e sua relevância para os estudos da linguagem, adotamos para este trabalho os estudos realizados sob a luz do ISD. Esses pesquisadores visaram à utilização dos gêneros como ferramentas para o ensino e seus pressupostos apontam que os textos são produtos da atividade de linguagem humana, produzidos a partir de gêneros textuais.

\footnotetext{
${ }^{1}$ As Diretrizes Curriculares para o Ensino de Línguas se pautam no construto teórico proposto por Bakhtin, o qual se utiliza do termo 'Gêneros Discursivos'. Para o referido termo utilizaremos gêneros textuais, devido ao construto teórico por nós adotado: Interacionismo Sociodiscursivo.
} 
O ISD considera a língua em constante mudança, assim como a sociedade. Desse modo, os gêneros são referências para o nosso agir com a linguagem e circulam nas mais diversas esferas de atividades sociais.

Considerando o gênero textual como objeto de ensino, Machado e Cristóvão (2006) apontam que sua transposição didática deve passar por transformações de modo a tornar o saber científico do gênero em saber ensinável. Para a efetivação da transposição didática do gênero, Dolz, Noverraz e Schneuwly (2004) sugerem que o trabalho seja sistematizado em sequências didáticas, as quais são definidas pelos autores como "um conjunto de atividades escolares organizadas, de maneira sistemática, em torno de um gênero textual oral ou escrito" (p. 82). Essas atividades têm por objetivo auxiliar no desenvolvimento das capacidades de linguagem necessárias para leitura e produção de um texto. Tais capacidades são divididas em: capacidades de ação (reconhecimento do gênero); capacidades discursivas (ligadas à infraestrutura geral do texto); e capacidades linguístico-discursivas (relacionadas às estruturas linguísticas adequadas ao contexto de produção).

A elaboração da SD permite a exploração do gênero textual de maneira adequada, transmitindo conhecimentos sobre o gênero ao mesmo tempo em que explore a sua esfera de circulação social. Sua estrutura seria composta pelas seguintes etapas:

a) Apresentação da situação de comunicação - expõe-se aos alunos o projeto de produção de um gênero textual, de modo que conheçam o objeto com que vão trabalhar e a situação de comunicação a ser executada;

b) Produção inicial- objetiva conhecer o que os alunos já dominam sobre o gênero. Tal produção deve orientar a construção dos módulos de ensino;

c) Módulos de atividade - propor atividades variadas para que as dificuldades dos alunos em relação ao gênero sejam confrontadas;

d) Produção finat possibilita ao aluno transpor as capacidades aprendidas durante as oficinas. Caso seja necessário, essa produção deve passar por processos de refacção, até que o texto final possa ser encaminhado ao objetivo de comunicação estabelecido. 
Logo, para nossa proposta, consideramos o desenvolvimento dessas etapas.

\section{Novas tecnologias e o ensino de línguas: multiletramentos}

As novas tecnologias vêm trazendo diversas mudanças às concepções de ensino e linguagem. Braga (2013) afirma que grandes mudanças acontecem na sociedade decorrente da migração das diferentes linguagens para o meio digital, sendo as variadas possibilidades de interação e comunicação da Web 2.0 responsáveis pelo surgimento de novos gêneros textuais. Ainda que as tecnologias não sejam as únicas a causar mudanças na linguagem, é perceptível que esta vem sendo muito impactada pela cibercultura, a qual é definida como "conjunto de técnicas materiais e intelectuais, de práticas, de atitudes, de modos e valores, que se desenvolvem juntamente com 0 crescimento do ciberespaço" (SILVA, 2004, p.4).

No que tange às modificações no cenário comunicacional, Braga (2013) afirma que se trata de um processo histórico de ressignificação e de continuidade a algo que já é familiar aos usuários. Ainda nessa perspectiva, podemos dizer, também, que as transformações pendem muito para a associação entre tecnologia e sociabilidade, configurando a cultura contemporânea, que tende a ser cíclica e, mais do que nunca, voltada para mixagens e ressignificações (LEMOS, 2005).

No que diz respeito à leitura, Coscarelli e Novais (2010) expõem que se trata de um processo dinâmico e aberto, cada vez mais complexo, que emerge a partir da ação de vários domínios de pensamentos. Além disso, as autoras apontam que a leitura desempenha um papel essencial frente aos textos digitais, pois eles integram tipos diferentes de linguagem e sempre trazem novidades em interface e elementos multimidiáticos.

Frente a essa reconfiguração da leitura, nos aliamos à perspectiva de estudos dos multiletramentos. A noção de multiletramentos advém do fato de considerarmos o letramento a partir de multiculturas e multissemioses. O termo foi primeiramente pensado pelo Grupo de Nova Londres (1996), do qual 
participavam pesquisadores de diversas regiões, reunindo-se a fim de refletir sobre novas práticas de ensino que dessem conta de abordar a multiplicidade cultural e semiótica dos textos em circulação (ROJO, 2012).

Os textos compostos por diferentes recursos ou mídias diferentes não podem ser separados em unidades de significados diferentes (LEMKE, 2010), isto é, ao utilizarmos imagens, vídeos ou áudio juntamente com texto escrito, estamos lançando mão de recursos complementares, que juntos constroem uma única unidade semiótica. Sendo assim, os recursos tecnológicos, como possibilidade de edição de imagens e vídeos, e a possibilidade de compartilhamento dessas produções devem ser levados para a escola, proporcionando com que os alunos sejam protagonistas, por meio de práticas de leitura e escrita que levem em conta a multiplicidade de textos, numa perspectiva que combina multiplicidade de recursos semióticos e expressa a multiplicidade de culturas presentes na sociedade.

\section{0 meme}

Como objeto de análise e produção do material didático, selecionamos um gênero que é altamente disseminado em redes sociais: o meme.

O meme é caracterizado por Recuero (2006) como um item socialmente difundido por "replicadores". De acordo com a autora, o termo 'replicadores', bem como o próprio termo meme, foi cunhado por Dawkins, em 1976, em sua obra intitulada $O$ gene egoísta, na qual ele relaciona a evolução da cultura à evolução dos genes. Nessa comparação, o meme representa o gene da cultura, isto é, ele é perpetuado por meio da ação dos replicadores.

Segundo Gunders \& Brown (2010), trata-se de uma expressão cultural que é passada adiante de uma pessoa ou grupo para outra pessoa ou grupo, daí a ideia de replicadores. Assim, os textos passam por um processo de leitura e compreensão, adoção do texto e decisão para replicação, ou seja, o leitor lê o meme, o compreende, cria empatia pelo que é exposto ou o acha engraçado, enfim, de algum modo o percebe como algo que faz parte de seu discurso e por conta disso o compartilha, fazendo sua replicação. Um exemplo interessante de 
um meme que passou por este processo foi um anúncio em vídeo de uma imobiliária na Paraíba, em que um pai de família fala sobre os benefícios de residir no determinado prédio e menciona que reuniu toda a família com exceção da filha Luiza, que estava no Canadá. A frase "menos Luiza, que está no Canadá", a partir da leitura do vídeo e assimilação da ideia, foi amplamente replicada em diversos meios além da internet.

Segundo Maciel e Takaki (2015), baseados em Lankshear e Knobel (2007), memes se referem a tudo o que pode ser copiado de uma mente para outra e podem ser encontrados em diversas esferas sociais como nos designs de moda, nos sons, nos desenhos, nos slogans, nas canções de ninar, na prática social de internautas geralmente criativos, entre outros.

Quando inseridos no contexto virtual, constituem-se como multi-hipermodais, podendo o produtor utilizar-se de imagem, vídeo, caricatura etc., para promover reflexão crítica, irônica e humorística. Sendo assim, para sua produção é necessário domínio de ferramentas de busca e edição de texto verbal e imagens.

Maciel e Takaki (2015) afirmam que "no contexto da linguagem, os memes representam modelos culturais de pensamentos, ideias, pressupostos, valores, esquemas interpretativos de fenômenos sociais simbólicos e comportamentais" (p. 57). Assim, há variadas possibilidades para a criação destes textos, desde os mais ligados ao humor aos mais engajados socialmente.

Para nosso trabalho, consideramos alguns memes que se relacionam às seguintes características: a) representação de fatos simples do cotidiano, para que o leitor perceba suas tarefas e atitudes representadas; b) referências cruzadas de meios culturais, como os musicais, fílmicos, televisivos e literários, por meio da intertextualidade; c) representações sociais generalizadas; d) críticas sociais a diversos segmentos e/ou comportamentos, como à política, por exemplo; e) utilização criativa de imagens, inserindo-as em contextos diferentes do original; f) ampla utilização de imagens de animais; g) representação de acontecimentos marcados temporalmente. 
Logo, vemos nesse gênero um potencial para o ensino da língua estrangeira, de modo a trabalhar variados tipos dessas produções a partir da perspectiva dos multiletramentos, buscando com que o aluno compreenda características do gênero, realize sua leitura crítica, percebendo recursos e intencionalidades presentes, para que, por fim, faça a produção de um meme utilizando recursos tecnológicos.

\section{O Facebook como principal veículo do gênero}

Com os recursos de interação e colaboração da $W e b$, é bastante comum, hoje em dia, a vivência social em um mundo textualmente mediado.

O Facebook foi lançado em 2004, nos Estados Unidos, sendo usado, primeiramente, como um site de comunicação entre os estudantes de Harvard e, posteriormente, ganhando proporção mundial. O site conta hoje com mais de 900 milhões de usuários em todo o mundo e é acessado diariamente em larga escala (HACHMAN, 2012).

O Facebook permite variadas possibilidades de ações, nas quais se percebe o uso de uma "ampla gama de funções discursivas, desde expressar opiniões [...], até relatar estados de espírito e outros sentimentos" (BARTON; LEE, 2015, p. 59). Os autores ainda apontam que

O facebook apresenta uma justaposição de espaços online, enquanto uma serie de formas síncronas e assíncronas tradicionais de interação CMC (comunicação mediada pelo computador) ocorre em um mesmo espaço. Além das atualizações de status, há um recurso de comentário que por vezes, age como um site para minifóruns de discussão (BARTON; LEE, 2015, p.59).

Há, também, a ferramenta de compartilhamento no site, que permite que informações acessadas em perfis de outros sejam compartilhadas na página do usuário. $\mathrm{E}$, além de usuários físicos, é possível criar páginas de qualquer conteúdo para compartilhamento de informações, inclusive comunidades criadas em torno de interesses específicos. Esta rede social torna- 
se o suporte ideal para textos como o meme, por conta da grande potencialidade de circulação e replicação.

Há diversas outras redes sociais que possibilitam esse recurso de compartilhamento de mídia, contudo, em nossa proposta, utilizamos, principalmente, exemplares de memes retirados do Facebook, considerando este contexto de circulação para trabalhar junto aos alunos a veiculação do meme e também para situar a produção final.

\section{A sequência didática}

Uma SD sempre pressupõe atividades a serem desenvolvidas conforme as necessidades reais da turma em que será trabalhada. Logo, as atividades aqui apresentadas representam possibilidades de abordagem sobre o meme, visando à leitura de alguns exemplares do gênero e ao trabalho com ferramentas tecnológicas, finalizando com uma proposta de produção do meme. Sendo assim, esta sequência didática, como quaisquer outras SDs que sejam frutos de publicações acadêmicas, deve ser adaptada conforme as necessidades do contexto em que for aplicada.

Para apresentação do desenvolvimento das atividades, optamos por realizar uma conversa com você, professor, mantendo uma linguagem direta a partir de imperativos.

\section{Apresentação da situação e primeira produção}

$1^{\circ}$ passo - Realize uma discussão com os alunos a partir de imagens ${ }^{2}$ com variados ícones de redes sociais ${ }^{3}$.

Questione-os sobre o uso de redes sociais: sobre quais os ícones eles reconhecem, sobre o porquê participar de uma rede social, etc.

\footnotetext{
2 Por conta de problemas na comunicação com os sites, não foi possível conseguir autorização para divulgação das imagens. Desse modo, para não prejudicar o conteúdo do texto, optamos por citar apenas os links que dão acesso a elas.

3 Um exemplo de imagem encontra-se disponível em:<http://www.pampulhasites.com.br/>. Acesso em: 26 set. 2015.
} 
A seguir, exponha para a turma que um dos pontos de chegada da Sequência Didática que será trabalhada será a criação de uma página no Facebook.

$2^{\circ}$ passo - Peça que os alunos formem grupos, observando para que haja pelo menos um dispositivo móvel (provavelmente um smartphone) no grupo.

Segundo o procedimento das SDs, deve-se fazer uma produção inicial do gênero a ser trabalhado, contudo acreditamos ser complexo pedir a produção do gênero em si, por conta da necessidade do uso de ferramentas de busca e edição de textos e imagens. Desse modo, entregue os questionamentos a seguir, os quais servirão apenas como uma produção coletiva sobre o gênero Meme.

Quadro 1: Sugestões de atividades.

1- Write how many students from your group participate in these social medias:

Facebook:

Snapchat: WhatsApp: Youtube:

\section{2- About Facebook:}

a) How often do you access it?

b) Do you consider yourself more like an author (creating posts) or receiver (viewing timelines and liking posts)?

c) What kind of content do you read the most on your Facebook page?

d) Do you think when we share posts we became co-author of the texts?

e) What do you know about meme?

f) What are the goals and characteristics of a meme?

g) What kind of technological tools can be used to create a meme? Do you know how to use them?

Fonte: Elaborado pelas autoras.

Abra para a discussão das respostas com todos os alunos, debatendo as ideias apresentadas, depois recolha as respostas para analisar mais cuidadosamente. 
Peça que abram suas contas no Facebook e mostrem para a sala o primeiro meme que encontrarem na timeline. Estipule um tempo para que façam a busca e, enquanto realizam a exposição para a sala, vá questionando a turma se a escolha se enquadra no gênero, podendo também fazer questões sobre o conteúdo dos memes.

Ao final das discussões, finalize a exposição da situação de comunicação: produção de memes para postagem na página do Facebook que criarão para a turma.

Essa atividade tem por objetivo observar se os alunos reconhecem 0 gênero e como realizam suas leituras. Além disso, procura observar 0 envolvimento dos alunos quanto ao contexto de circulação do meme: as redes sociais. Logo, a atividade envolve as capacidades de ação.

\section{Módulos de ensino}

\section{Módulo 1 - Contexto de Produção e Circulação}

Acesse com os alunos (da maneira mais apropriada ao contexto de ensino) a página da comunidade ggagno Facebook <https://www.facebook.com/9gag?fref=ts>.

- Os alunos devem observar como se dá a construção da página de uma comunidade e em que aspectos ela se diferencia da página de usuários.

- Peça para os alunos irem até a seção "sobre" e observem as características daquela página em específico: Data de início; Descrição; Informações gerais; Missão; Website.

- Questione os alunos a respeito do título da página e sobre a citação que aparece em informações gerais, "In the end, everything is a gag." (Charles Chaplin), indagando-os sobre por que esta frase pode ser considerada "informação geral" sobre a página.

- Faça uma leitura da página, observando os tipos de postagens.

- Peça para que os alunos acessem a seção "fotos" e procurem um meme específico que esteja entre as primeiras imagens (Para isso, o professor 
deve acessar a página anteriormente e escolher a imagem). Outras opções são: o professor projetar a imagem retirada da página ou deixar que os próprios alunos escolham uma imagem.

- A partir da postagem, os alunos devem observar as seguintes informações: Author of the posting; Author's social role; Receiver; Receiver's social role; Purpose; Theme; Character; Publication source.

Leve-os a perceberem que não há menção a uma pessoa como autor, apenas à página da qual ela faz parte.

\section{Módulo 2 - Analisando Exemplares de Memes}

Realize a leitura de variados estilos de memes, pois suas características são variadas, fazendo questionamentos de interpretação e características linguísticas.

A cada imagem lida, observe a identificação dos alunos em relação aos textos. Uma possibilidade é combinar a utilização do conceito "curti" e "não curti", fazendo alusão à prática realizada no Facebook.

A seguir, para cada característica a ser explorada em sala de aula, apresentamos alguns exemplos de memes $^{4}$ que podem ser utilizados.

Representação de atividades comuns do dia a dia:

Leia os memes com os alunos e questione-os ${ }^{5}$ :

Quadro 2: Sugestões de atividades.

(a) Do you feel represented in these texts?

(b) Do both texts represent the same time?

(c) Although Meme 2 doesn't have written text, can we say it tells a story? Why? What language does it use?

(d) Which is the verbal tense used in the Meme 1? Why?

2207520000.1443548155./10154049094446840/?type=3\&theater> Acesso em: 26 set. 2015. A segunda refere-se ao fato de derrubarmos o celular no rosto quando deitados. Disponível em: <https://www.facebook.com/9gag/photos/pb.21785951839.-

2207520000.1443549571./10153954259606840/?type=3\&theater>. Acesso em: 26 set. 2015. 
Fonte: Elaborado pelas autoras.

Leve os alunos a concluírem sobre essa característica do gênero: empatia e autorreconhecimento, pois se espera que o leitor se sinta representado por também já ter passado por tais situações.

\section{Intertextualidade}

A intertextualidade tem papel fundamental para a compreensão dos memes. Comente com os alunos sobre essa característica, falando sobre a importância da experiência pessoal quanto ao consumo de produções artísticas. Entregue a eles uma atividade contendo memes $^{6}$ que façam referência a textos de variadas origens, como músicas, filmes, séries etc.

Quadro 3: Sugestões de atividades.

(a) Look at the memes below and write the texts/characters they are related. Write the kind of artistic production they come from.

Fonte: Elaborado pelas autoras.

6 Referente à obra Alice in Wonderland (Lewis Carroll) - Disponível em: <https://www.facebook.com/9gag/photos/pb.21785951839.-

2207520000.1443548909./10154035958416840/?type=3\&theater>. Acesso em: 26 set. 2015. Referente ao filme Batman - Disponível em: <http://www.vitamin-ha.com/amazing-animalmemes/vh-funny-animals-654/>. Acesso em: 26 set. 2015.

Referente ao file Titanic - Disponível em: <https://www.facebook.com/9gag/photos/pb.21785951839.2207520000.1443550669./10153868022711840/?type=3\&theater>. Acesso em: 26 set. 2015. Referente à série Game of Thrones - Disponível em: <https://www.facebook.com/9gag/photos/pb.21785951839.2207520000.1443549571./10153954256331840/?type=3\&theater>. Acesso em: 26 set. 2015. Referente à música Moves like Jagger (Maroon 5) - Disponível em: <http://weknowmemes.com/2013/04/moves-like-jaguar/>. Acesso em: 26 set. 2015. 
Socialize as respostas e questione se todos os alunos conseguiram entender os memes, reconhecendo o texto original. Realize também uma leitura sobre qual a relação desses textos com os originais. 
Representações sociais

Representações sociais também podem ser observadas, ou seja, visões socialmente difundidas a respeito de um grupo. Para discutir essa característica, divida os alunos em dois grupos, um com meninos e outro com meninas. Entregue a eles os textos ${ }^{7}$ e peça que discutam entre si como neles é representada a diferença entre os gêneros e o que pensam sobre essa visão. Depois, realize um debate entre os dois grupos, os quais devem apresentar seus pontos de vista através de argumentos.

\section{$3 \sqrt{2}$ Crítica social}

Trabalhe a crítica social a alguns seguimentos, como política e empresas, por exemplo.

Quadro 4: Sugestões de atividades.

Atividades: Meme 1-Refere-se ao comportamento de políticos ${ }^{8}$.

(a) What is the criticism in the text?

(b) Which is the figure of speech used?

(c) What are the characters used to illustrate? Do they have voice?

(d) Whose is the voice present in the text?

(e) Do you consider yourself part of this voice? Why?

Atividades: Meme 2 - Refere-se a uma Multinacional de fast-food 9 .

${ }^{7}$ Disponível em: <http://imgur.com/gallery/joWEQvU>. Acesso em: 26 set. 2015.

Disponível em: <https://www.pinterest.com/pin/236720524140427420/>. Acesso em: 26 set. 2015.

Disponível em: <https://www.facebook.com/9gag/photos/pb.21785951839.2207520000.1443548155./10154047029856840/?type=3\&theater>. Acesso em: 26 set. 2015.

8 Disponível em: <https://www.facebook.com/9gag/photos/pb.21785951839.2207520000.1443548155./10154053653161840/?type=3\&theater >. Acesso em: 26 set. 2015.

$9 \quad$ Disponível em: <https://www.facebook.com/9gag/photos/pb.21785951839.2207520000.1443550797./10153813497776840/?type=3\&theater>. Acesso em: 26 set. 2015. 

(a) What is the criticism in the text?
(b) What is the importance of the character for this criticism?
(c) Whose is the voice present in the text?
(d) How is the character's speech represented?
(e) Why can we say there is irony in the text?
(f) What is your opinion about the subject?

Fonte: Elaborado pelas autoras.

Ainda em relação a este tema, trabalhe o uso de ironia e sarcasmo através da personagem Wonka, do filme Willy Wonka \& the Chocolate Factory $(1971)^{10}$, que realiza diversas críticas a comportamentos ou posturas assumidas pelos indivíduos. Para isso, leia os textos, discuta-os com os alunos e realize as atividades a seguir.

Quadro 5: Sugestões de atividades.
(a) Who is this character?
(b) Who has voice, the character or the reader?
(c) What is the tone of the text? Which is the figure of speech used?
(d) Why can this character represent this tone?
(e) What is relationship between the character's posture and the written texts?
(f) We notice a dialogue. How is the interlocutor's voice introduced?
(g) Are the interrogative forms being used according to written English? Why?
(h) Which is the interjection used in the pictures? What does it mean?

Fonte: Elaborado pelas autoras.

\footnotetext{
${ }^{10}$ Disponível em: <https://www.pinterest.com/pin/247627679487619115/>. Acesso em: 26 set. 2015.

Disponível em: <http://www.christianforums.com/threads/post-a-willy-wonkameme.7848137/>. Acesso em: 26 set. 2015.

Disponível em: <http://memecrunch.com/meme/V1V/every-time-i-hear-i-hate-mondays>. Acesso em: 26 set. 2015.
} 
35 Criatividade a partir das imagens

Trabalhe a apropriação de imagens variadas e sua associação a uma representação de um acontecimento que costuma ser comum, fazendo esta relação a partir da coesão entre a situação e a expressão do personagem.

A partir destes tipos de memes, explore como o uso da expressão de tempo when é importante para criar associação das expressões/imagens às atividades cotidianas, com as quais muitos se identificam.

Exemplos: Whenyou and your friend are thinking the same thing ${ }^{11}$

When mom calls you by your full name ${ }^{12}$

Whenyou prove someone wrong $^{13}$

Quadro 6: Sugestões de atividades.

(a) Explain why these pictures could be associated to these daily situations.

(b) Do you agree with these representations?

(c) Do the texts give voice to the characters?

(d) Which is the expression of time used?

(e) Which is the verbal tense used in all the texts? What does it mean?

Fonte: Elaborado pelas autoras.

Seguindo a ideia base de apropriação de imagens, trabalhe, também, a utilização de imagens de animais, aos quais, geralmente, se costuma atribuir vOz $^{14}$.

${ }^{11}$ Disponível em: <https://imgflip.com/i/brsem>. Acesso em: 26 set. 2015.

12 Disponível em: <https://www.pinterest.com/pin/183592122285050122/>. Acesso em: 26 set. 2015.

${ }^{13}$ Disponível em: < http://memes.com/img/930879>. Acesso em: 26 set. 2015.

14 Disponível em: <https://www.facebook.com/9gag/photos/pb.21785951839.2207520000.1443549036./10154000628626840/?type=3\&theater>. Acesso em: 26 set. 2015.

Disponível em: <http://www.beheadingboredom.com/kids-draw-spiders-on-a-dalmatian/>. Acesso em: 26 set. 2015.

Disponível em: <https://www.pinterest.com/pin/151644712427322583/>. Acesso em: 26 set. 2015. 
Quadro 7: Sugestões de atividades.

(a) Do the texts 1 and 3 represent animals or human's actions? And the text 2?

(c) Whose is the voice in the texts?

(d) Compare texts 2 and 3 about direct and indirect speech.

Fonte: Elaborado pelas autoras.

\section{Representação temporal}

Finalize a exploração dos textos refletindo sobre a filiação temporal dos memes, questionando se os textos vistos até agora demonstram a época em que foram feitos.

Depois, leiam os dois textos sugeridos e peça que identifiquem a que acontecimentos estão relacionados, a saber: o texto $1^{15}$ relaciona-se ao descobrimento da existência de água em Marte, em setembro/2015; o texto $2^{16}$ combina o lançamento do filme Batman VS Superman (2015) ao resultado de Brasil e Alemanha na Copa de 2014, em que a Alemanha venceu por 7x1.

Por fim, discuta novamente com os alunos sobre a circulação dos memes, apontando outras redes sociais em que estão presentes (como WhatsAppe Snapchat)e realize uma síntese sobre o estudo realizado.

Quadro 8: Síntese sobre características do gênero Meme.
1) Todos os textos utilizaram imagens que servem para complementar o texto escrito de maneira fundamental para a compreensão da mensagem;
2) O objetivo dos textos é alcançar um caráter humorístico, mesmo quando realiza críticas;
3) A linguagem utilizada é mais informal;
4) Há uso de recursos variados da língua, entre eles a ironia, metáfora, discurso direto, expressões temporais etc.;
5) Podem ser determinados temporalmente devido a acontecimentos específicos ou ser mais genéricos, representando fatos e pensamentos cotidianos;

15 Disponível em: <https://www.facebook.com/9gag/photos/pb.21785951839.2207520000.1443548155./10154061227926840/?type=3\&theater>. Acesso em: 26 set. 2015.

16 Disponível em: <https://www.facebook.com/9gag/photos/pb.21785951839.2207520000.1443549571./10153949245321840/?type=3\&theater>. Acesso em: 26 set. 2015. 
6) Podem utilizar personagens variados, inclusive pessoas públicas e animais;

7) Podem utilizar a intertextualidade com produções artísticas;

8) Abusam da criatividade.

Fonte: Elaborado pelas autoras.

\section{Módulo 3 - Trabalhando com a Edição de Imagens e Textos Verbais}

Há variados recursos para se combinar imagens e textos verbais em um só texto. Assim, neste momento, é necessário que se faça um levantamento das possibilidades disponíveis em seu contexto, para que se escolha o meio que achar mais apropriado. Problematize com os alunos sobre a produção de memes e a necessidade do domínio de recursos tecnológicos, discutindo possibilidades. Por fim, realize uma atividade que explore como fazer montagem com várias imagens e sobreposição de texto verbal.

Algumas opções para este trabalho são: Paint (programa presente em quase todos os computadores); sites e aplicativos próprios para a criação de memes, como o Imgur.com/memegen e Meme generator.

\section{Produção final}

$1^{\circ}$ momento - Crie a página no Facebook com os alunos: o título, imagens do perfil e da capa, descrição, informações gerais, missão. Elejam quais serão os responsáveis pela página.

$2^{\circ}$ momento - Proponha aos alunos que criem seus memes a partir de imagens do cotidiano. Os alunos podem tirar suas fotos ou procurar e usar imagens de filmes, TV, de animais etc. $O$ importante é observar uma imagem e, através das expressões do personagem, associá-la a uma situação completamente diferente da inicial.

Estipule modelos que podem ser seguidos, como: a) o que utiliza o when para expressões decorrentes de situações cotidianas; b) o que atribui fala/diálogo ao personagem. 
Caso o professor prefira, para que os alunos possam interagir, a produção do gênero pode ser realizada em duplas ou trios, podendo, ainda, pedir mais de um modelo para o grupo.

Além disso, após trabalhar com o gênero em forma de imagem, o professor pode trabalhar o meme em vídeos, os quais são, também, muito presentes nas redes sociais.

\section{Conclusão}

Considerando o contexto social discutido, procuramos elaborar uma proposta que atendesse ao alunado atual, unindo o procedimento sequência didática às práticas de multiletramentos, ao trabalhar um gênero com o qual os jovens mantêm contato diariamente. Acreditamos que trabalhar textos como esses na sala de aula desafia os alunos a compreenderem as estratégias estéticas utilizadas em suas construções, fazendo com que seus olhares para aqueles textos se modifiquem e eles possam ser confrontados com um universo de possibilidades de leitura. Esperamos, assim, que este trabalho proporcione ao aluno perceber melhor o mundo que está em sua volta, tanto em relação às informações contidas no texto e suas representações, quanto ao tipo de linguagem utilizada no processo de sua construção.

\section{Referências}

BAKHTIN, Michael. Estética da criação verbal. São Paulo: Martins Fontes, 2003.

BARRETO, Raquel Goulart. Tecnologia na formação de professores: o discurso do MEC. Educação e pesquisa. São Paulo, v.29, jul./dez. 2003. p. 271-286.

BARTON, David; LEE, Carmen. Linguagem online: textos e práticas digitais. São Paulo: Parábola Editorial, 2015.

BRAGA, Denise Bertoli. Uma breve reflexão sobre a história da escrita. In:BRAGA, D.B. Ambientes digitais reflexões teóricas e práticas. São Paulo: Cortez, 2013. 
BRONCKART, Jean Paul. Atividades de linguagens e discursos. por um interacionismo socio-discursivo. São Paulo: EDUC, 2009.

COSCARELLI, Carla Viana; NOVAIS, Ana Elisa. Leitura: Um processo cada vez mais complexo. Letras de Hoje, Porto Alegre: v.45, n.3, p. 35-42, jul./set. 2010.

DAWKINS, Richard. O Gene egoísta. Coleção O Homem e a ciência, v.7. Belo Horizonte: Itatiaia, 2001.

DOLZ, Joaquim; NOVERRAZ, Michele; e SCHNEUWLY, Bernard. Sequências didáticas para o oral e a escrita: apresentação de um procedimento. In: DOLZ, J. e SCHNEUWLY, B. Gêneros orais e escritos na escola. Campinas: Mercado de Letras, 2004. p. 95-128.

GUNDERS, John; BROWN, Damon. The complete idiot's guide to memes. New York: Alpha, 2010.

HACHMAN, Mark. Facebook now totals 901 millions users, profit slip. Disponível em: <http://www.pcmag.com/article2/0,2817,2403410,00.asp>. Acesso em: 26 set. 2015.

LEMKE. Jay L. Letramento metamidiático: transformando significados e mídias. Trabalhos em Linguística Aplicada. Campinas, v.49. n.2. p. 455-479. jul./dez. 2010.

LEMOS, André. A cibercultura-remix. In: Seminário Sentidos e processos da mostra Cinético Digital. São Paulo: Itaú Cultural, 2005.

MACHADO, Anna Raquel; CRISTOVÃO, Vera Lúcia Lopes. A construção de modelos didáticos de gêneros: aportes e questionamentos para o ensino de gêneros. Linguagem em (Dis)curso, Tubarão, v.6, n.3, set./dez. 2006. p. 547573.

MACIEL, Ruberval Franco; TAKAKI, Nara Hiroko. Novos letramentos pelos memes: muito além de ensino de línguas. In: JESUS, D. M. de.; MACIEL, R. F. (Org.). Olhares sobre tecnologias digitais: linguagens, ensino, formação e prática docente. Coleção Novas Perspectivas em Linguística Aplicada. Vol. 44. Campinas: Pontes Editores, 2015.

NEW LONDON GROUP. A pedagogy of multiliteracies: Designing social features. Harvard Educational Review; Spring 1996, p. 60-91.

RECUERO, Raquel da Cunha. Memes e dinâmicas sociais em weblogs: informação, capital social e interação em redes sociais na internet. Intexto. Porto Alegre: UFRGS, v.2, n.15, p. 1-16, jul./dez. 2006. 
ROJO, Roxane. Pedagogia dos multiletramentos: diversidade cultural e de linguagens na escola. In: ROJO, R.; MOURA, E. Multiletramentos na escola. São Paulo: Parábola Editorial, 2012.

SCHULER, Carly; WINTERS, Niall; WEST, Mark. The future of mobile learning: implications for policy makers and planners. UNESCO. Paris, 2013.

SILVA, Marco. Indicadores de interatividade para o professor presencial e online. Diálogo Educacional. Curitiba, v.4,n.12, p.93-109, maio/ago. 2004. 